\title{
NOVAS TECNOLOGIAS, CAPITALISMO DE DADOS E A DINÂMICA DE PROTEÇÃO DOS DIREITOS FUNDAMENTAIS
}

\author{
Noemi Leandro da Silva* \\ GustaVo СоTOMACCI**
}

RESUMO

O presente artigo busca compreender a evolução histórica dos direitos fundamentais, o avanço das novas tecnologias na era digital em que vivemos e novo modelo de capitalismo de dados. Dada a importância dos três assuntos em nossa sociedade buscamos compreender como as tecnologias que viabilizam o capitalismo pautado na obtenção e processamento de dados pessoais, atualmente ativo mais valioso das empresas, impacta a dinâmica de proteção dos direitos fundamentais já consagrados, e traz à discussão questões como o modelo de liberdade vigiada que presenciamos com o advento da internet, redes sociais e modernos aparelhos celulares; além da lógica de facilidade e comodidades que impute, de maneira sutil, o capitalismo de dados que nos torna cada vez mais reféns das escolhas feitas pelas grandes empresas. E até mesmo a aparente liberdade democrática que pode estar se tornando uma democracia manipulada, ou seja, uma imposição revestida de aparente escolha da maioria. Por fim, demonstraremos a proteção de dados pessoais em uma sociedade com grandes avanços tecnológicos que se torna tão fundamental em erguê-la ao rol de direitos de maior proteção jurídica, os direitos fundamentais.

Palavras-chave: Tecnologias. Dados. Direito.

NEW TECHNOLOGIES, DATA CAPITALISM AND THE DYNAMICS OF PROTECTION OF FUNDAMENTAL RIGHTS

\section{ABSTRACT}

This article seeks to understand the historical evolution of fundamental rights, the advancement of new technologies in the digital age in which we live and a new model of data capitalism. Given the importance of the three subjects in our society, we seek to understand how the technologies that enable capitalism based on the collection and processing of personal data, currently the most valuable asset of companies, impact the dynamics of protection of fundamental rights already enshrined, and bring up issues as the model of guarded freedom that we witnessed with the advent of the internet, social

* Noemi Leandro da Silva. Graduada em Direito - Universidade Metodista de São Paulo. E-mail: noemileandro@gmail.com

** Gustavo Cotomacci, professor mestre, orientador no Curso de Direito na Universidade Metodista de São Paulo - UMESP. E-mail: gustavo.cotomacci@metodista.br. 
networks and modern cell phones, the logic of ease and amenities that subtly imposes the data capitalism that makes us increasingly hostage to the choices made by the great companies. And even the apparent democratic freedom that may be becoming a manipulated democracy, that is, an imposition coated with the apparent choice of the majority. Finally, we will demonstrate the protection of personal data in a society with great technological advances that it becomes so fundamental to raise it to the list of rights of greater legal protection, fundamental rights.

Keywords: Technologies. Data. Right.

\section{INTRODUÇÃO}

O presente artigo busca tratar sobre os direitos fundamentais e as novas tecnologias de modo a demonstrar ao longo do texto que o capitalismo e sua colisão na dinâmica dos direitos fundamentais, pois, o avanço tecnológico possui impactos em diversos âmbitos da vida humana, principalmente quando leva-se em consideração aspectos sociais, econômicos, culturais e religiosos.

Isso porque as tecnologias se modernizam em velocidade exponencial e devem alterar por completo a dinâmica da humanidade com o passar dos anos. Acrescenta-se a isso o fato de que, desta vez, há de se compreender que o direito deve buscar acompanhar as evoluções da sociedade, sobretudo porque aguardar a configuração dos fatos para só então regulamentar as regras de conduta, como costumeiramente ocorre no direito, pode trazer prejuízos irreparáveis ao meio ambiente, a existência humana e aos direitos fundamentais que podem ter seu rol acrescido diante da nova dinâmica da sociedade tecnológica.

A sociedade tecnológica vem sofrendo alterações no seu modo de vida, de comunicação, de interação social, de trabalho, de organização econômica, de formação educacional-acadêmica, de transporte, entre tantos outros. Até mesmo as noções mais solidificadas de Estado, nação e povo estão sendo questionadas ou rompidas diante da inexistência de barreiras entre pessoas de qualquer lugar no mundo digital.

Ante a tudo isso a discussão dos direitos fundamentais não apenas permanece, se amplia e se torna ainda mais complexa. Principalmente quando se levantam questionamentos sobre o direito de liberdade e a exposição face as formas de comunicação demonstradas por meio da internet, nesse diapasão há que se levantar alguns questionamentos: é considerado uma invasão de privacidade sem precedentes? Em uma sociedade tecnológica, em que

o capitalismo se baseia na obtenção e tratativas de dados como diferencial competitivo podemos dizer que a proteção dos dados pessoais se torna um direito fundamental?

Formada está a tríade que pretende analisar: direitos fundamentais, novas tecnologias e capitalismo de dados. Passa-se a breve explanação dos elementos. Os direitos fundamentais são uma criação do homem, fruto da nossa evolução, da nossa conscientização do que é o ser humano e como tal, são a verdadeira expressão do essencial para vida humana digna.

A evolução dos direitos fundamentais retrata os avanços históricos da hu- 
manidade, bem como a adequação daquilo que é primordial para existência do homem. Nasceram da necessidade de frear o Estado autoritário, o grande Leviatã, e garantir a liberdade individual ( $1^{\text {a }}$ geração), o reconhecimento do ser humano autônomo e livre.

Do reconhecimento do eu, a evolução da consciência para o nós, a coletividade humana que a despeito de suas diferenças e particularidades deve ser tratada com igualdade de oportunidades pelo Estado ( $2^{a}$ geração). Com a evolução dos tempos, o avanço da economia, a intensificação da coletividade de povos, que ainda que possuidores de histórias, riquezas e características diferentes, em sua essência todos humanos, nasce o reconhecimento da fraternidade, do direito coletivo e difuso, daquilo que é de toda a gente nascida e a nascer ( $3^{a}$ geração).

No enredo da história mundial o capitalismo se torna o sistema regente de toda nossa organização social, termômetro da riqueza das nações e das pessoas, símbolo primordial de poder. Nos seus primórdios, muito atacado por aqueles que acreditavam em outras formas de organização, em especial no socialismo seu grande potencial rival, mas o tempo demonstrou a viabilidade do capitalismo frente aos anseios do homem, assim como a inviabilidade de outros sistemas.

Ante a complexidade da questão, percebe-se a necessidade de equilibrarmos a exploração de recursos naturais esgotáveis sob pena de desaparecermos do planeta. A história também se conta pelos avanços e descobertas que homem fez, faz e continuará fazendo e cada vez mais rapidamente e com soluções inimagináveis. Chegamos ao século XXI e a era das novas tecnologias, do conhecimento multiplicado, ou da falsa sensação de conhecimento que todos possuem, pois vivemos a sociedade do Google, Facebook, Instagram e Twitter.

As novas tecnologias estão revolucionando nossa forma de viver, de trabalhar, de comprar, de vender, de se relacionar, a moeda está se transformando em algo virtual e todos os profissionais além de seu ofício precisam minimamente conhecer as tecnologias e ferramentas digitais. Tudo isso tem suas conveniências, reforça o capitalismo, mas nos assusta quando pensamos que a nossa forma humana pode estar sendo modificada ou até mesmo violada.

Todo este contexto nos leva a tríade complexa, porém extremamente necessária de estudos e discussões, que este trabalho se propõe a fazer, ainda que de forma inicial. Os diretos fundamentais com sua alma protetiva do ser humano; novas tecnologias e o auge incrível da criação humana que estamos vivendo e viveremos ainda mais intensamente nos próximos 5, 10, 15 ou 20 anos; o capitalismo de dados é a nova riqueza da humanidade que tem transformado as empresas de tecnologias nas mais valiosas. Tudo isso tem transformado o homem em produto?

Diante disso a relevância e complexidade a que este artigo se propõe, não. Não temos como fugir de onde chegamos e do que virá nos próximos anos, mas temos o dever individual e coletivo de discutirmos a proteção do humano, a vivência digna e a não coisificação de nossa essência. Por mais que o dinheiro, as novas tecnologias e suas facilidades sejam algo que nos agrade, o limite da defesa do essencialmente humano precisa existir. 
Este artigo não visa proteções ou garantias que limitem o avanço das novas tecnologias, muito pelo contrário, reconhece a beleza e grandiosidade dessas, mas entende que assim como em outros tempos o humano teve que ser protegido de outros agentes, agora também precisa ser garantido diante dos excessos que podem ocorrer, e desta vez, até mesmo de forma imperceptível e/ou mascarada.

No âmbito do direito o desafio da modernização da ciência jurídica, da adequação das leis ao novo mundo, da modulação do operador do direito para uma realidade que não se encontra ou não se materializa somente no mundo físico, o virtual talvez esteja mais presente e mais factível que o real. Cumpre ao direito confrontado com essa realidade pensar adiante, antever os riscos na busca mais que necessária da proteção dos direitos fundamentais e da dignidade humana.

Mas cumpre-lhe também entender a era das novas tecnologias e tutelar o direito destes avanços, reconhecendo também os benefícios trazidos e não apenas uma posição conservadora, arcaica e resistente que inviabiliza o novo ou empobrece o debate e o ajuste social, no qual o direito é tão essencial

A questão central é: como as novas tecnologias estão impactando e impactarão os direitos fundamentais e o próprio entendimento de quais são esses direitos em uma sociedade de que sai do capitalismo de produção e serviços para o capitalismo de dados.

Tal realidade é nova e ainda pouco discutida. A legislação brasileira mais específica regulamentando a obtenção, utilização e descarte de dados que são a essência das novas tecnologias como a IA - Inteligência Artificial, Machine Learning, Data Base entre outras é recente e entrará em vigor a partir de agosto de 2020 (Lei Geral de Proteção de Dados Pessoais - Lei 13.709/2018).

Tal lei pode alterar a dinâmica de utilização e avanço de tais tecnologias uma vez que a regulamentação dos dados pessoais pode, de certa forma, restringir sua utilização, balizando a expansão das novas tecnologias ou incentivando o mercado ilegal de obtenção de dados. Mas também é a forma de garantir os direitos individuais de privacidade e liberdade e de nossos dados pessoais.

Destaque-se que todos os sistemas das empresas de serviço, redes de relacionamentos, governos e suas agências estão embasados na combinação de dados para obtenção de variáveis respostas que direcionem a oferta de produtos, tomada de decisões e a manipulação de eleições como se verá.

Objetiva-se então entender, através de pesquisas à legislação, doutrinas, artigos, livros, documentários, filmes e afins, a evolução que nos trouxe a era das novas tecnologias, analisando assim, como tais alterarão e impactarão a dinâmica dos direitos fundamentais, em especial o direito de proteção dos dados pessoais.

\section{DOS DIREITOS FUNDAMENTAIS}

Para a explanação dos direitos fundamentais é mandatória a reflexão filosófica sobre o homem. Refletir sobre a essência humana, aquilo que nos difere dos demais seres viventes, aquilo que nos conecta, nos torna gênero humano inde- 
pendentemente de raça, cor, credo, sexo, idade, condição social, enfim, aquilo que nos dizeres bíblicos nos faz a imagem e semelhança de Deus: "Criou Deus, pois, o homem à sua imagem, à imagem de Deus os criou: homem e mulher os criou" (GÊNESIS 1.27), aquilo que é a essência, o nosso ser, a designação peculiar do humano (SHEDD, 1997).

De alguma maneira, seja pela criação ou pela evolução das espécies, o homem se diferenciou, obteve ou conquistou um status quo que faz dele o único ser pensante, o único ser consciente de sua existência e do fim dela, o único que percebe a si e ao outro de forma racional e lógica, o único, portanto, que precisa de uma condição para viver e não apenas para existir.

Os direitos fundamentais são frutos da consciência humana que ao longo do tempo foi se desenvolvendo e entendendo a condição de dignidade que o homem precisa para viver, entendendo que garantir tal condição é fundamentalmente um direito e que este direito emana da própria essência de ser humano.

Assim o homem começou a modular seus direitos, em uma evolução gradativa, moldando seu modo de organização social, a constituição e delimitação do Estado e o reconhecimento do direito do "eu" (indivíduo) e da "gente" (coletivo). Disso surgem gradualmente os direitos do homem, antecessores do que hoje em boa medida conhecemos com direitos fundamentais, evoluindo e se adequando a história. Nos dizeres de Norberto Bobbio:

\footnotetext{
Do ponto de vista teórico, sempre defendi - e continuo a defender, fortalecido por novos argumentos - que os direitos do homem, por mais fundamentais que sejam, são direitos históricos, ou seja, nascidos em certas circunstâncias, caracterizados por lutas em defesa de novas liberdades contra velhos poderes, e nascidos de modo gradual, não todos de uma vez e nem de uma vez por todas (BOBBIO, 2004, p.5).
}

As circunstâncias de vida dos seres humanos fazem parte de um conjunto de questões sociais que formam a sua realidade, o surgimento da Constituição Federal de 1988, buscou garantir que esse indivíduo consiga viver em sociedade de maneira plena nos mais variados aspectos concernentes a dignidade da pessoa humana, direito de ir e vir, liberdade de expressão, direito de votar, proteção elencada as crianças e adolescentes, acesso à justiça, à saúde, à educação são diversas e variadas as formas relacionadas aos aspectos de direito.

As alterações nas dinâmicas sociais, econômicas, culturais e até mesmo religiosas são uma constância de nossa história evolutiva, e ao direito sempre coube se adaptar a tais acontecimentos. No tempo atual, vivemos mais um destes momentos disruptivos, não sendo demais afirmar que tal mudança pode ser a mais radical e complexa pela qual a humanidade já passou.

Os direitos fundamentais são uma criação do homem, fruto da nossa evolução, da nossa conscientização do que é ser humano e como tal, são a verdadeira expressão do essencial para vida humana digna. Também a evolução dos direitos 
fundamentais retrata os avanços históricos da humanidade, bem como a adequação daquilo que é primordial para existência do homem.

A história tecnológica também se conta pelos avanços e descobertas que homem fez, faz e continuará fazendo e cada vez mais rapidamente e com soluções inimagináveis. Tudo isso tem suas conveniências, reforça o capitalismo, mas nos assusta quando pensamos que a nossa forma humana pode estar sendo modificada ou até mesmo violada.

No âmbito do direito o desafio da modernização da ciência jurídica, da adequação das leis ao novo mundo, da modulação do operador do direito para uma realidade que não se encontra ou não se materializa somente no mundo físico, o virtual talvez esteja mais presente e mais factível que o real.

Cumpre ao direito diante dessa realidade pensar adiante, antever os riscos na busca mais que necessária da proteção dos direitos fundamentais e da dignidade humana. Mas cumpre-lhe também entender a era das novas tecnologias e tutelar o direito destes avanços, reconhecendo também os benefícios trazidos e não apenas uma posição conservadora, arcaica e resistente que inviabiliza o novo ou empobrece o debate e o ajuste social, no qual o direito é tão essencial.

A tratativa do que são os direitos fundamentais, bem como demais conceitos simultâneos, necessários a estruturação de um sistema jurídico que positive e garanta o exercício pleno de tais direitos. Fábio Gesser Leal e Rafael Giordani Sabino (2017), apresentam uma visão panorâmica dos direitos fundamentais, ligando-os ao fenômeno do Constitucionalismo e apresentando como marco inicial a Magna Carta Inglesa de 1215.

Seguindo a evolução histórica mundial dos direitos humanos Bill of Rights do Estado de Virgínia, no ano de 1776, e finalmente, com a Declaração dos Direitos do Homem e do Cidadão, editada na Revolução Francesa de 1789. Normas cogentes que trazem a positivação dos direitos inerentes ao homem, que até então não passavam de reinvindicações políticas e filosóficas. Completam o breve histórico citando Ingo Wolfgang Sarlet (2018):

A história dos direitos fundamentais é também uma história que desemboca no surgimento do moderno Estado constitucional, cuja essência e razão de ser residem justamente no reconhecimento e na proteção da dignidade da pessoa humana e dos direitos fundamentais do homem (SARLET, 2018, p.38).

O autor trata os direitos fundamentais como essência basilar do Estado Democrático de Direito trazendo à tríade: direitos fundamentais, Constituição e Estado Democrático e Social de Direto. Tal trilogia apresenta interdependência e nexo, sendo os direitos fundamentais e a Constituição os limites normativos ao poder estatal e o Estado Democrático Social de Direito o garantidor dos direitos fundamentais e das condições de gozo deles.

Diversos termos são utilizados na referência aos direitos fundamentais: "direitos humanos", "direitos naturais", "direitos do homem", direitos individuais", entre distintas terminologias que fazem referência ao tema. A compreensão da 
linguística é essencial para compreensão dele, uma vez que a linguagem se renova e traz a interpretação conforme referencial sociocultural do momento.

Assim sendo, Leal e Sabino (2017, p. 208) em referência a José Afonso da Silva (2005), definem direitos fundamentais como: "aqueles direitos atinentes a situações jurídicas sem as quais a pessoa humana não se realiza, não convive e, às vezes, nem mesmo sobrevive". Já nas palavras de Luigi Ferrajoli, também citado na obra referenciada temos que:

São 'direitos fundamentais' todos aqueles direitos subjetivos que correspondem universalmente a "todos" os seres humanos enquanto dotados do status de pessoas, cidadãos ou pessoas com capacidade de agir; entendido por 'direito subjetivo' qualquer expectativa positiva (de prestações) ou negativa (de não sofrer lesões) ligada a um indivíduo por uma norma jurídica; e por 'status' a condição de um sujeito, prevista também por uma norma jurídica positiva, como pressuposto de sua idoneidade para ser titular de situações jurídicas e/ou autor dos atos que são exercício destas (FERRAJOLI, 1995, p. 31 - grifo do autor).

Direitos fundamentais são todos aqueles que garantem ou preservam a condição de dignidade que todo indivíduo deve ter em sua existência, e como tal, são também conditio sine qua non para existência de um Estado Social Democrático de Direito. Cabe ainda destacar, na conceituação dos direitos fundamentais, a natureza jurídica a qual pertencem.

De maneira majoritária o entendimento doutrinário é de que são direitos subjetivos. Alguns vão além dizendo que são direitos subjetivos garantidores de liberdades e outros afirmam ainda que são direitos subjetivos de natureza principiológica. É o que vemos em Leal e Sabino (2017) em referência respectivamente a Luís Roberto Barroso (2011), José Joaquim Gomes Canotilho (1993) e Paulo Mascarenhas (2010):

Os direitos fundamentais possuem natureza de normas constitucionais definidoras de direitos subjetivos que investem seus beneficiários em situações jurídicas imediatamente desfrutáveis, a serem executadas por prestações positivas ou negativas, exigíveis do Estado ou de outro eventual destinatário da norma. E ainda de acordo com o autor, "por direito subjetivo, [...] entende-se o poder de ação, assente no direito objetivo, e destinado à satisfação de um interesse. Tais direitos são direitos subjetivos de liberdade. Impende salientar, ademais, que os direitos fundamentais, dada sua alta dimensão valorativa, são recorrentemente tidos como princípios, apesar de referida natureza não ser uma regra. (BARROSO, 2009, p. 221-222).

De forma sucinta Flávia Martins Andréa Silva (2006, p. 76) encerra a conceituação do tema: "os direitos fundamentais são a criação de todo um contexto histórico-cultural da sociedade". Nesse aspecto a importância dos direitos fundamentais encontram cerne na proteção do ser humano de modo que a posi- 
tivação desses direitos busca consolidar diretrizes sociais, administrativas, de preservação do indivíduo.

Observa-se que os direitos fundamentais são a positivação dos direitos humanos que em caráter resumido garantem a proteção da dignidade humana. Imperiosa constatação também é de que a dignidade da pessoa humana está para existência jurídico-filosófica do indivíduo como o oxigênio está para a existência do ser vivente, sendo assim, a relação direitos fundamentais e dignidade da pessoa humana é umbilical nos dizeres de Leal e Sabino (2017) que para demonstrarem tal relação citam Barroso (2011), em leitura filosófica sobre o tema:

A dignidade da pessoa humana é o valor e o princípio subjacente ao grande mandamento, de origem religiosa, do respeito ao próximo. Todas as pessoas são iguais e têm direito a tratamento igualmente digno. A dignidade da pessoa humana é a ideia que informa, na filosofia, o imperativo categórico kantiano, dando origem a proposições éticas superadoras do utilitarismo: a) uma pessoa deve agir como se a máxima da sua conduta pudesse transformar-se em uma lei universal; b) cada indivíduo deve ser tratado como um fim em si mesmo, e não como um meio para a realização de metas coletivas ou de outras metas individuais. As coisas têm preço; as pessoas têm dignidade. Do ponto de vista moral, ser é muito mais do que ter. (BARROSO, 2011, p. 252).

Concluem Leal e Sabino (2017) que não há dignidade da pessoa humana sem direitos fundamentais e vice-versa. Destacam ainda que na Constituição Brasileira de 1988 a vinculação dos direitos fundamentais à dignidade humana não guarda a mesma intensidade na proteção de todos os direitos fundamentais relacionados no título em questão, há uma valoração diferente entre o direito fundamental de proteção a vida e direito também fundamental de recebimento do $13^{\circ}$ salário pelo empregado.

Nesse sentido, vemos como a proteção dos direitos fundamentais fora evoluindo ao longo da história das Constituições do Brasil, desde a Carta Magna de 1824 na qual tivemos a concepção de direitos fundamentais implementada, ainda que de forma mais restrita conforme demonstra Groff (2009, p. 107): “Também o art. 179, que trazia um extenso rol de direitos civis e políticos dos cidadãos brasileiros, era o último artigo da Constituição. Isso demonstra que a Constituição não destinou um espaço de relevância para os direitos fundamentais".

Ou seja, nesse aspecto ainda na Constituição de 1824 já existia a previsão de direitos fundamentais, porém, de forma expressa. Todavia, a sequência cronológica dos artigos, inclusive nos dias atuais, denota a importância de determinado direito, não há que se falar em falta de importância, mas sim em um escalonamento de importância é o que se percebe ao ler o artigo primeiro da Constituição Federal vigente.

Em 1891 houve com o fim da monarquia brasileira a proclamação da República o que trouxe mudanças dentro do aspecto institucional e de conservação de direitos, sendo um marco muito importante para o atual constitucionalismo brasi- 
leiro, vejamos segundo Groff (2009, p. 110) como era distribuído os direitos fundamentais nessa Constituição:

Ao rol de direitos da Constituição de 1824 foram acrescentados os seguintes direitos e garantias: extensão dos direitos aos estrangeiros; igualdade republicana; liberdade de culto; casamento civil e gratuito; cemitérios seculares; ensino leigo nos estabelecimentos públicos; fim da religião de Estado; direitos de reunião e associação; ampla defesa; perda da propriedade em decorrência de desapropriação por necessidade e utilidade pública, mediante indenização prévia; abolição das penas de galés e do banimento judicial; abolição da pena de morte, reservadas as disposições da legislação militar em tempo de guerra; habeas corpus; propriedade intelectual e de marcas e instituição do júri. É importante destacar que alguns acréscimos se deram em função da separação entre o Estado e a Igreja. A Constituição trazia um rol apenas demonstrativo de direitos, deixando em aberto a possibilidade do reconhecimento de outros direitos não-enumerados, "mas resultantes da forma de governo que ela estabelece e dos princípios que consigna" (art. 78). Isso representa uma inovação em comparação com a Constituição de 1824. (GROFF, 2009, p. 110)

Dessa forma, percebemos que os moldes atuais de Constituição e preservação dos direitos humanos encontra cerne no contexto histórico ligado a consolidação de direitos, lutas de classes, compreendendo assim o porquê da Constituição Federal de 1988 manter esse caráter garantista efetivo, apesar das dificuldades encontradas ao longo dos conflitos sociais para efetivação desses direitos as delimitações doutrinárias e jurisprudenciais cumprem justamente esse papel.

$\mathrm{O}$ aspecto tecnológico ganha um espaço significativo na sociedade ao conseguir, por meio do celular, estreitar os laços de comunicação e rapidez do acesso às informações sobretudo no que tange a comunicação, ainda que se tenha problemas referente a reclusão física há que se ressaltar as contribuições do avanço tecnológico.

Nos Poderes Executivo, Legislativo e Judiciário essa temática é ainda mais acentuada, pois, a automatização dos processos físicos traz benefícios inenarráveis, tanto para questão do acesso ao processo, quando a distribuição de prazos, a preservação da natureza também poder ser um aspecto a ser ressaltado.

A Carta Magna de 1988 também dá aos direitos fundamentais a proteção máxima de cláusulas pétreas conforme artigo 60, § 4º IV. Leal e Sabino (2017) destacam o entendimento doutrinário majoritário sobre o tema, que também é acompanhado pelo Supremo Tribunal Federal, na interpretação de que tal proteção é dada apenas ao núcleo essencial dos princípios e institutos de preservação dos mesmos e não de forma absoluta. Nossa Constituição destinou um título inteiro aos direitos fundamentais. O Título II - Os Direitos e Garantias Fundamentais se subdivide em cinco capítulos, os quais passamos a detalhar conforme explanação de Silva (2006), principalmente sobre a temática dos direitos individuais e coletivos como sendo eles direitos relacionados a concepção de pessoa humana, a sua existência e personalidade, tais como à vida, à igualdade, à dignidade, à honra e à liberdade, entre outros. 
Todos encontram previsão legal no artigo $5^{\circ}$ da Constituição Federal de 1988, nesse diapasão os direitos sociais são aqueles que estão ligados as liberdades individuais que o Estado deve garantir, inclusive com a finalidade de proporcionar condições de vida melhores em especial aos menos favorecidos.

À luz de Barroso (2011) cumpre destacar que na perspectiva moderna e liberal, a Constituição tem a pretensão muito maior de influenciar o ordenamento jurídico e a ordenação de um Estado novo, muito mais do que ser mera escrita ou positivação. Desta forma o autor classifica a Constituição sob dois aspectos:

\begin{abstract}
a) do ponto de vista político: o poder constituinte reconstruiu o Estado, instituindo órgãos de poder e disciplinando a relação entre eles e deles com a sociedade;b) do ponto de vista jurídico: reparte em duas visões: i. material: refere-se ao conteúdo das normas que organizam o poder político, definem os direitos fundamentais, consagra valores e define os fins públicos a serem realizados;ii. formal: refere-se à posição da Constituição no sistema jurídico, norma fundamental e superior, reguladora e limitadora do modo de produção das demais normas. (BAROSO, 2011, p. 134).
\end{abstract}

Dito isso, vemos que além da essência da Constituição e de sua supremacia no ordenamento jurídico, ela guarda forte relação na criação ou recriação de um Estado de Direito fundamentado na preservação do humano, do social, do democrático. Nas palavras de Barroso (2011, p. 97): “A Constituição, portanto, cria ou reconstrói o Estado, organizando e limitando o poder político, dispondo acerca de direitos fundamentais, valores e fins públicos e disciplinando o modo de produção e os limites de conteúdo das normas que integrarão a ordem jurídica por ela instituída".

Necessário é destacarmos a privacidade, intimidade e liberdade na garantia da dignidade humana. Trata-se de direitos fundamentais previsto em nossa Carta Suprema como direitos individuais. São aqueles direitos fundamentais de primeira geração que garantem o indivíduo enquanto ser humano, limitando a atuação do Estado, bem como a interferência que qualquer outro terceiro naquilo que é a esfera mais intima de proteção do homem. Seus direitos de se resguardar quando assim entender e sua liberdade de escolha, sua autonomia, sua vontade aqui de se expor.

Vejamos que direitos individuais também são categorizados enquanto direitos fundamentais, principalmente porque são processos e direitos relacionados a aspectos sociais, no mesmo sentido percebemos" os direitos individuais são direitos fundamentais próprios do homem-indivíduo, porque titularizados e exercidos por pessoa individualmente considera em si, com a delimitação de uma esfera de ação pessoal (MORAES, 2017, p.193).

À liberdade, direito individual cujo objeto é mesmo a própria liberdade. Isso para que mais à frente possamos entender a questão de obtenção e utilização de dados pessoais e se isso fere tais direitos, ou mesmo se os dados pessoais devam ingressar na categoria de direitos individuais fundamentais. Dentre esses direitos, 
o relacionado à privacidade que é previsto no artigo $5^{\circ}$ inciso $\mathrm{X}$ da Constituição Federal diz respeito à maneira de se compreender diversos aspectos pessoais do indivíduo sobretudo englobando a intimidade, honra, imagem das pessoas, inviolabilidade de domicílio.

Por outro lado, existe um debate consolidado sobre a privacidade e a liberdade de expressão, quais seriam os limites de ambas. Vejamos o que diz Álvaro Carvalho Pinto Pupo:

[...] a privacidade é ainda maior do que o inciso $X$ do artigo $5^{\circ}$ da Constituição Federal e não deve ser confundida com um único conceito apresentado neste artigo ou mesmo da Constituição Federal. O que exatamente é a privacidade, conteúdo é pouco abordado na jurisprudência dos principais tribunais do país, em regra, os ministros parecem adotar o mesmo princípio de Solove e reconhecer a aplicação ou violação da privacidade nos casos concretos, sem, contudo, busca definir ou delimitar demais esse importante conceito. Já foi apontado que a privacidade pode ser considerada como um conjunto de outros direitos, dentre os quais o direito à liberdade. Este se apresenta de diversas formas, dentre elas, a liberdade de expressão. No Brasil, a liberdade de expressão é prevista constitucionalmente no art. $5^{\circ}$, incisos IV, VI, IX, XIII, XIV e art. 220. (PUPO, 2017, p. 64)

À privacidade é concebida como um princípio e direito positivado que busca a consolidação dos direitos individuais e fundamentais do ser humano, isso porque todos os cidadãos possuem aspectos relacionados à sua privacidade que precisam ser preservados. Nesse sentido, ambos os direitos à intimidade, privacidade e liberdade são amplos e irrestritos não podendo ser censurados ou diminuídos, são previsões incontestáveis do direito brasileiro, sendo inclusive referenciados para demonstrar que o indivíduo dentro da sociedade precisa agir em conformidade com a lei, porém sem que seja restringido demais aspectos.

Vale ressaltar que é necessária a realização da proteção da privacidade, intimidade e a liberdade como forma de consolidar o acesso à dignidade da pessoa humana, isso porque a questão que envolve aspectos pessoais solidifica a personalidade no indivíduo, e ainda que existem evoluções tecnológicas, o indivíduo deve prevalecer sobre as inovações, a proteção e garantia dos direitos deve ser consolidada.

Quando lidamos com esses limites é pertinente elencarmos uma ligação com aspectos tecnológicos, isso que com o avanço latente dessa tecnologia a liberdade, privacidade e intimidade passaram ainda mais por um filtro perigoso, ou seja, com as redes sociais ataques relacionados a ambos esses aspectos se tornaram mais latentes sobre a perspectiva de ferir o direito do próximo sob o subterfúgio do anonimato.

É justamente por isso que a legislação busca evoluir constantemente para abarcar esses aspectos, que ligados a realidade social dos indivíduos brasileiros precisam constantemente de normas que fundamentem dentro da perspectiva tecnológica ataques relacionados a liberdade de expressão, intimidade e privacidade. 
Um exemplo é o caso Carolina Dieckmann bastante repercutido no Brasil, a partir da violação da liberdade, intimidade e privacidade da atriz principalmente porque houve um vazamento de seus documentos pessoais constrangendo-a dando assim, lugar para elaboração da lei que busca proteger esses aspectos atualmente.

\section{DO CAPITALISMO DE DADOS E DAS NOVAS TECNOLOGIAS}

O capitalismo surgiu e se consolidou pela produção de bens e serviços, vimos o surgimento e avanços de grandes indústrias pelo mundo, tais como a automobilística, têxtil, eletroeletrônica, entre tantas outras. Seguido do surgimento exponencial de empresas prestadoras de serviços, como bancos, seguradoras, companhias aéreas, para citarmos algumas.

Atualmente, as maiores empresas tecnológicas conhecidas pela sociedade estão ligadas ao mercado das redes sociais e de comunicação telefônica tais como Facebook, Google e Apple. São empresas de tecnologia, que mantém o monopólio das informações e, por conseguinte, abrangem dentro de suas diretrizes os crimes de ódio cometidos por usuário que ferem a liberdade, intimidade e privacidade de outros usuários.

A rentabilização em cima da manutenção de dados entre os usuários, é realizada a partir de capturas e armazenagem, que buscam combinar os dados e revelar o perfil de cada cliente e principalmente, sua tendência de consumo e comportamento futuro. Vivemos o capitalismo de dados onde as empresas de tecnologias passaram a liderar os rankings de vendas e de giro de capital.

O capitalismo do século XX era estruturado nas pessoas, tanto quando as considerava como força de produção (empregados) como enquanto clientes dos produtos e serviços produzidos, fazendo assim, gerar a roda da economia. O capitalismo de dados do século XXI tira o fator humano da sua lógica estrutural, o substituindo por dados e algoritmos.

Diferente da necessidade de balancear a renda da população com os pre-
ços dos bens produzidos, para mover a "roda da economia", do capitalis-
mo do século XX, o capitalismo de vigilância rompe com esta premissa,
criando uma independência estrutural, onde a população deixa de ser ne-
cessária como fonte de clientes e empregados. A independência estrutu-
ral significa que a empresa, no capitalismo de vigilância, necessita apenas
dos dados do indivíduo, com os quais constrói perfis que se tornarão seus
ativos. A hiperescala através de crescente automação, e tecnologias esca-
láveis em nuvens, permite que as empresas operam com efetivos cada vez
menores, tendo os algoritmos como "meio de produção". Esta indepen-
dência estrutural das empresas em relação à população é uma questão de
excepcional importância à luz da relação histórica entre capitalismo de
mercado e democracia (CARIBÉ, 2019, p.6).

Dessa feita, percebe-se que não temos uma data exata que marque o início do capitalismo de dados ${ }^{1}$, sabemos que ele surgiu dado o advento da Internet, que

1 Capitalismo de vigilância ou dados: termo criado pela acadêmica da Harvard Business School 
veio como algo maravilhoso, abrindo uma infinita quantidade de possibilidades a todos que ali estivessem, uma plataforma inovadora e democrática. Mas por diversos fatores ou lacunas, técnicas, comportamentais, legais, econômicos, sociais e estruturais o capitalismo de vigilância foi sendo construído.

Há indícios de que a Amazon foi a primeira empresa a trabalhar de forma assertiva com os chamados "agentes inteligente":

\begin{abstract}
Ao "observar" o comportamento dos clientes, com o objetivo de ofertar livros com maior chance de compra, a Amazon pavimentou o capitalismo de vigilância, em outras palavras, a Amazon extraía dados de clientes, e os modelava na busca de padrões, e através de homofilia, estabelecia relacionamentos, produzindo indicações para o cliente, visando "aprimorar" a sua experiência (CARIBÉ, 2019, p.6).
\end{abstract}

Com diversos avanços e aprimoramento dos modelos de captura e tratamento dos dados, hoje temos diversas empresas praticando puramente o capitalismo de dados: Google, Facebook, Apple, WhatsApp, Alibaba, Netflix, Waze, Spotify, Youtube, Twitter, entre tantas outras que fazem dos dados pessoais, redes de relacionamento dos usuários ou clientes e perfil de consultas, compras etc. seu ativo.

Dado os avanços de capacidade de armazenamento de dados na nuvem, maior velocidade da internet, aparelhos smartphones mais sofisticados, de avanço das redes sociais à captura de informações a respeito de cada indivíduo tem aumentado gradativamente o quantitativo de usuários, em decorrência do contato e a possibilidade de conhecer novos usuários.

Reconhecimento facial através de fotos postadas, geolocalização (que permite mapear os locais mais frequentados), captura de voz que os smartphones e tabletes

Shoshana Zuboff para classificar o novo tipo de capitalismo que monetiza dados adquiridos por vigilância. (ZUBOFF, 2019).

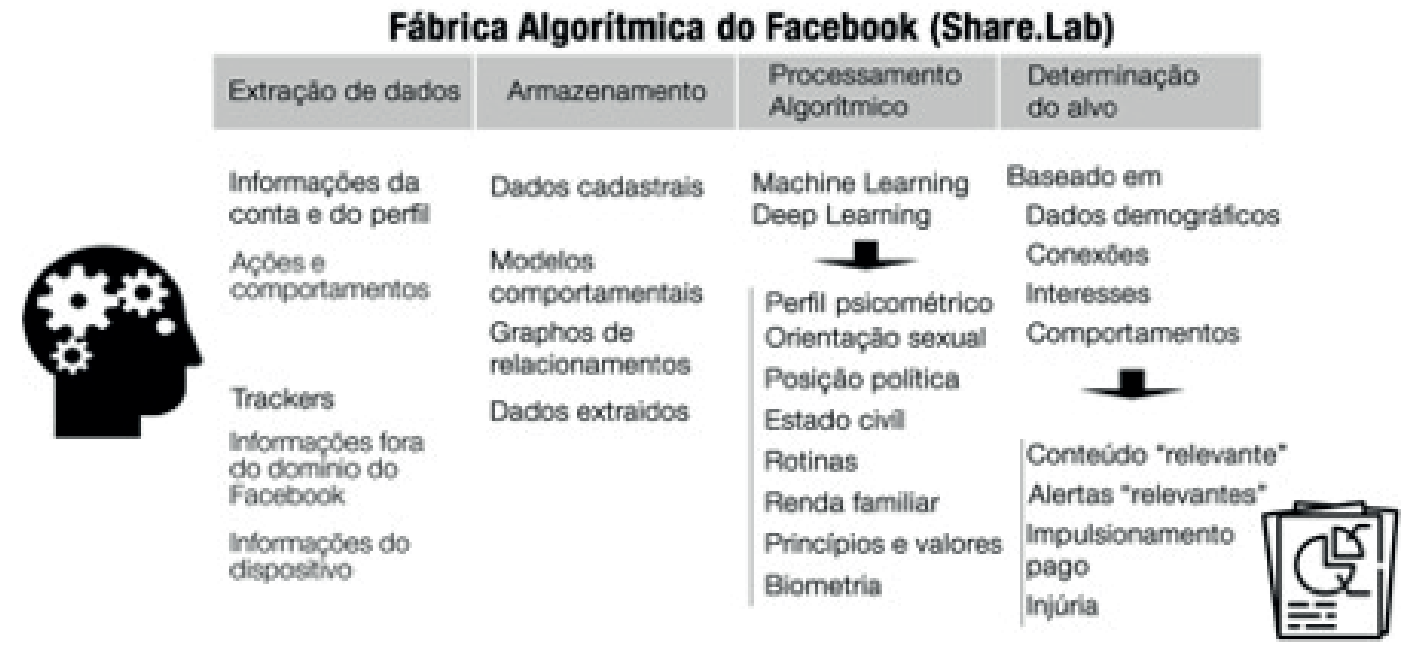

modernos permitem. Caribé (2019) demonstra como o Facebook, provavelmente o maior propulsor de tudo isso trabalha os dados citando um infográfico que trata sobre a fábrica algorítmica do Facebook (Share.Lad). 


\title{
Figura 1. A fábrica algorítmica do Facebook
}

Fonte: Share Lab, 2016

\section{Caribé (2019) complementa citando outro estudo do laboratório:}

\begin{abstract}
Em outro estudo, do laboratório intitulado "Invisible Infrastrutures: mobile permissions" (SHARE LAB, 2015), que detalha as informações do dispositivo, é apontado que o aplicativo do Facebook acessa 42 funções e sensores do smartphone, dentre elas leitura e gravação de agenda, caderno de telefones, SMS, e log de telefones, e ainda acessa câmeras, microfones, lista de redes wifi próximas, e informações de geoposicionamento (CARIBÉ, 2019, p.9).
\end{abstract}

Até aqui fica claro, como o sistema do capitalismo ocorre e que quando este é relacionado ao capitalismo de dados é invasivo e fere os direitos de privacidade e intimidade. Com a utilização de algoritmos de Facebook, e de tantas outras empresas, consegue determinar o quê e em que momento exibir ao usuário. Ora tais ferramentas podem prestar um grande desserviço à democracia, à liberdade de escolha pois podem facilmente serem utilizadas para interesses manipuladores de governos e empresas. $\mathrm{O}$ avanço do capitalismo de dados se viabilizou pelo avanço da Internet. Para Caribé (2019, p.6-7):

\begin{abstract}
Evolução nos hábitos e velocidade de acesso à Internet, o desenvolvimento tecnológico, desenvolvimento de mercados, e práticas e padrões de desing e de programação para Internet, foram fatores importantes para este desenvolvimento [...] A banda larga trouxe a conectividade permanente à Internet, produzindo novos hábitos de uso. As interações passaram a ser em tempo real.
\end{abstract}

Todo avanço do capitalismo de vigilância se deve também a um novo comportamento social das pessoas, que aceitaram a beleza do mundo virtual e se dispuseram a não apenas utilizá-lo, mas também, a exporem suas vidas, a compartilhar dados pessoais, fotos, localizações em uma espécie de diário virtual público. Atraídas também pela possibilidade de vigilância do outro. Sobre tal comportamento Caribé (2019) cita Zygmunt Bauman e David Lyon, dizendo:

Para Bauman e Lyon (2013), a arquitetura das tecnologias eletrônicas permitem formas de controle com diferentes faces, inclusive compartilhando as características ligadas ao consumo e entretenimento, apontando para vigilância e autovigilância como novas perspectivas comportamentais do indivíduo frente às tecnologias, que inclusive sentem-se felizes e motivados a compartilharem detalhes íntimos de suas vidas pessoais tais como fotos, fatos, eventos e pensamentos (CARIBÉ, 2019, p.8).

Complementando o cenário que viabilizou o avanço rápido e exponencial do capitalismo de dados temos o surgimento e penetração dos smartphones que de 
aparelhos de luxo se popularizaram e se tornaram item de primeira necessidade até mesmo para as classes mais baixas. Mesmo com o elevado custo de aquisição dos aparelhos hoje se torna uma exceção alguém que não os tenha e inimaginável para todos nós ficarmos sem eles. Caribé (2019) destaca:

O caso dos smartphones no Brasil mostra que a resposta do mercado é importante, com $5 \%$ da população Brasileira com smartphone em 2009, aplicações que fazem uso da mobilidade não teriam economia de escala para subsistirem. Com a penetração próxima dos $90 \%$ eles se tornaram a principal ferramenta auxiliar do capitalismo de vigilância. (CARIBÉ, 2019, p.8).

Verificamos que o avanço das novas tecnologias fundamentou a estrutura do capitalismo de dados, mas é preciso destacar que tal sistema soube se valer muito bem de uma abordagem encantadora, bem como de lacunas, explorando o desconhecido, aquém muitas vezes da ética e das normas, tecendo um mercado e regras que viabilizem sua atuação sem limites.

Nesse cenário o capitalismo de dados é expresso pelo crescimento econômico produzido pelo setor tecnológico, e assim tanto a sociedade quanto o direito sofrem impacto dessas mudanças conceituais existentes, assim, buscou-se compreender como ocorre esse processo e de que forma o direito poderá regulamentar essa situação de modo a proteger o usuário e cidadão de prováveis aspectos negativos vinculado à rede da tecnologia.

O capitalismo de dados é uma realidade e seu avançar também é algo de fácil previsão, ante a isso a necessidade de regulamentação, em especial para proteger os usuários que por mais apaixonados que estejam por todo este mundo incrível das novas tecnologias se passa muitas vezes por deslumbrado e não percebe os riscos e violações de direitos que está sofrendo. A primazia da pessoa humana deve se sobrepor e todos os encantos, facilidades e riquezas.

O desrespeito a direitos fundamentais como intimidade, privacidade e liberdade, ao princípio maior da dignidade da pessoa humana clamam por uma regulamentação urgente, bem como anunciam que dados pessoais possa ser o mais novo direito fundamental da humanidade. A questão da regulamentação da proteção de dados pessoais avança em todo o mundo, nos dizeres de Caribé (2019):

Considerando que os dados são o principal ativo do capitalismo de vigilância, impor limitações à sua extração, transporte, processamento e armazenamento, tem sido objeto de políticas de dados pessoais. A Europa é pioneira, e já possui um marco legal para proteção de dados pessoais conhecido por GDPR. No Brasil, a Lei Geral de Proteção de Dados Pessoais (LGPD) sancionada em 2018, entrará em vigor em 2020 (CARIBÉ, 2019, p.9).

A evolução dos dados e o crescimento tecnológico se alastra com uma velocidade incomum, ante a isso a troca quase que diária de aparelhos eletrônicos que bus- 
cam cada vez mais aprimorar o contato tecnológico. Essa evolução pode ser compreendida como uma riqueza para o mundo, principalmente sobre o aspecto capitalista.

Há que se ressaltar que intuito do presente trabalho não é argumentar sobre uma legislação repressiva aos crescimentos tecnológicos, mas, sim que estimule o crescimento de forma clara e protegendo esse usuário e cidadão brasileiro, a face do capitalismo de dados pode se revestir de capa não ética e oportunista para driblar regulamentações e direitos, mas temos avanços indescritíveis por exemplo para medicina. $\mathrm{O}$ avanço de um setor não pode significar o retrocesso de direitos batalhados e conquistados ao longo da história, como bem vimos no primeiro capítulo deste trabalho. É urgente olharmos todos os riscos e novas proteções que ecoam na primazia da proteção da dignidade da pessoa humana.

O capitalismo de dados suscita questões que excedem ao direito, temos discussões que envolvem a democracia das nações, a saúde mental e física das pessoas, o comportamento social. Caribé (2019) diz:

A cronologia e sistematização dos eventos permitiu expor, que o Capitalismo de Vigilância soube aproveitar cada oportunidade criada, transformando-as sempre em lucro, e aprimorando seus negócios de comercialização de comportamentos futuros. Este desenvolvimento foi, e continua sendo intimamente ligado a adoção de novas tecnologias pelo mercado, produzindo uma economia de escala, indispensável ao big data. Acordos, fusões e aquisições de empresas, supriram a demanda voraz de dados e comportamentos codificados, e continuam suprindo [...] Este tem em seu DNA uma prática predatória, que está consumindo a privacidade, liberdade, autonomia, sanidade mental e estado de direito [...] Violar regras parece ser uma das características operacionais do capitalismo de vigilância, que está sempre desenvolvendo à margem da lei e da ética, tencionando-as, até que sejam flagrados, expandindo para um novo campo invisível, de forma cíclica [...] Este debate, de profunda importância para o futuro da humanidade, está apenas começando (CARIBÉ, 2019, p.10).

O futuro do capitalismo de dados está intimamente ligado ao futuro da humanidade e como tal, a muito interessa a Ciência Jurídica, pois tal transformação social requer a adequação do sistema de normas garantidoras de direitos e reguladoras das relações sociais e comerciais. Dessa forma, compreender que o exercício do princípio da dignidade da pessoa humana depende de aspectos ligados não apenas aos aspectos físicos do ser humano, mas, também em tudo em sua volta que lhe satisfaça.

Compreendendo que o pressuposto do princípio da dignidade da pessoa humana é inerente ao ser humano e deve ser observado em todo o contexto que envolve o ser humano de modo a proteger sua existência nos mais variados âmbitos: social, psicológico, tecnológico e assim o direito, não obstante, deve buscar consolidar cada vez mais os direitos relacionados aos mais variados conteúdos que 
apresentem risco para sociedade.

\title{
DA PROTEÇÃO DE DADOS
}

Pelo exposto até, aqui fica claro que a detenção e combinação de dados, em especiais dados pessoais sensíveis, é poder político e econômico, pois servem de ferramenta de manipulação de comportamentos futuros. Também tratamos dos direitos fundamentais de privacidade, intimidade e liberdade, bem como do princípio da dignidade da pessoa humana que, de forma muito clara, são violados quando da obtenção e utilização desses dados, sem contar a questão da ética e da democracia que ficam à mercê de grandes grupos econômicos e/ou governos autoritários enrustidos de democracia.

Necessário é destacar que não apenas o poder econômico tem incentivado e feito uso cada dia maior e mais complexo dos dados, os governos também perceberam a brecha e a cada dia investem mais fortemente na questão, na maioria com a justificativa de segurança nacional, por vezes, trazendo à tona o direito individual fundamental de privacidade em choque com o bem comum, talvez tenha que ser ressignificado ou mesmo menos protegido.

Eugênio Facchini Neto e Karine Silva Demoliner (2018) explanam bem a questão:

\begin{abstract}
Não é demais lembrar que paralelamente ao mercado, o poder público também passou a investir pesadamente no desenvolvimento de tecnologias capazes de aprofundar ainda mais o conhecimento e controle sobre cada indivíduo, especialmente para "vigiá-lo" constantemente e, com isso, talvez evitar novos ataques terroristas e/ou crimes de qualquer espécie. Passou, assim, a fomentar pesquisas sobre "digitais cerebrais", com o intuito de "mapear a memória" dos indivíduos, de sorte a buscar em seu inconsciente registros de fatos pretéritos e indícios de que tenham deles participado (leia-se, invadir a sua privacidade e, em maior intensidade, a sua dimensão mais íntima - e que deveria ser inviolável), tudo sob o pretexto de garantir a segurança da coletividade (FACCHINI NETO; DEMOLINER, 2018, p. 56)
\end{abstract}

Pensar em como tudo está muito bem construído, interligado e principalmente disfarçado de algo bom seja para o usuário consumidor ou para o cidadão, é assustador. A violação de direitos e a manipulação seja para induzir uma compra pequena seja para forjar o resultado de uma eleição demonstra o perigo e a urgência de discutirmos o assunto. Facchini Neto e Demoliner (2018) lembram bem do escândalo do Facebook e da Cambridge Analytica que trataremos mais adiante:

Não é demais lembrar que os dois acontecimentos de natureza política e econômica mais relevantes dos últimos anos, a saber a eleição de Donald Trump para presidente dos Estados Unidos da América, o BREXIT (saída do Reino Unido da União Européia) tiveram seus cursos definidos por empresa especializada na manipulação (ilícita) de dados pessoais, o que restou desvendado no que passou a ser conhecido como 
"escândalo Facebook - Cambridge Analytica" (FACCHINI NETO; DEMOLINER, 2018, p.134).

Vemos que não somente a proteção dos dados é urgente como o reforço ou a não resistência da ressignificação de direitos pois não se trata de uma evolução social que demanda nova interpretação hermenêutica destes e sim, de uma tentativa muito bem articulada de violação em prol do poder econômico e/ou político. Neste sentido Facchini Neto e Demoliner destacam:

\begin{abstract}
Esse repensamento atinge mais profunda e diretamente a noção de privacidade. Após o "11 de setembro" a privacidade passou a ser vista como verdadeiro empecilho / obstáculo à segurança pública, o que fortaleceu o discurso (cada vez mais forte, e a cada dia com mais adeptos) de que sua importância no contexto dos direitos fundamentais diminui sobremaneira, de sorte que deve ceder sempre que estiver em colisão com outros princípios e garantias fundamentais. Rodotá adverte, inclusive, que há quem sustente que a privacidade perdeu, nessa "era do terror", seu status de direito fundamental, sendo facilmente superada por "legislações de emergência". (FACCHINI NETO; DEMOLINER, 2018, p. 89).
\end{abstract}

É assustador o ataque muito bem articulado do poder econômico e público aos direitos fundamentais, em especial à privacidade. $\mathrm{O}$ terror, assim como qualquer crime, deve e tem que ser combatido pelo Estado, mas não a custo de direitos e garantias individuais, em um contexto que claramente percebemos que o que se busca é o poder, ou seja, os dados que lhe proporcionem tal condição. Neto e Demoliner (2018) após detalhada narrativa histórica do conceito de privacidade e de seu valor para liberdade das pessoas ante o Estado e o Mercado bem ressaltam:

O que se quer, enfim, é garantir a todos os benefícios da sociedade da comunicação e informação em que inexoravelmente vivemos, impedindo, porém, os abusos na manipulação de pessoas. Este é o grande desafio contemporâneo (FACCHINI NETO; DEMOLINER, 2018, p.135).

Mundialmente falado, a legislação de proteção de dados de maior destaque, por ser pioneira e fonte de inspiração para outras legislações inclusive a brasileira, é a GDPR - General Data Protection Regulation da União Europeia que regulamenta a questão em todo o bloco político e econômico formado por países europeus.

Em 27 de abril de 2016, o Parlamento Europeu e o Conselho Europeu emitiram o Regulamento (UE) 2016/679 referente à proteção das pessoas singulares no tratamento e circularização de dados pessoais. Tal regulamento entrou em vigor em 25 de maio de 2018. Dado o curto espaço de tempo para adequação isso tem causado alvoroço no mercado tecnológico, pois notícias dizem de gigantes como Google, Facebook, Instagram e WhatsApp já estão sofrendo processos bilionários por desrespeitarem as regras europeias.

É de se destacar que a Legislação Europeia inovou ao expandir os conceitos clássicos de proteção, conceituou dados pessoais, bem como dados sensíveis dando a estes categoria especial de proteção, também evidenciou que o consentimento 
deve ser livre, específico, informado e inequívoco. O regulamento também ressalta o direito de ser excluído, direito ao esquecimento, direito de se opor (negar o uso de seus dados), direito de retificação de dados incorretos, direito de transparência (acesso sobre o armazenamento e processamento dos dados), e por fim, o direito de portabilidade dos dados.

Caso a União Europeia tenha regulamentado a questão dos dados com rigor que o tema demanda, ele parece não ocorrer no Estados Unidos da América. Após polêmica fala o presidente da Apple, Tim Cook, em outubro de 2018 dizendo que empresas de tecnologia estavam criando um "complexo industrial de dados", o Senado americano se viu "obrigado" a agir e apresentou uma proposta legislativa federal.

Mas tal proposta está longe de ser uma regulamentação sobre a coleta, armazenamento e utilização de dados pessoais, ela propõe ampliar os poderes de uma agência reguladora de interesses dos consumidores (FTC - Federal Trade Comission) para que ela regule questões relacionada a privacidade. Nos dizeres de Demócrito Reinaldo Filho (2018):

O problema é que os Estados Unidos não têm um conjunto sistematizado de leis de proteção à privacidade, como ocorre na União Europeia. Diferentemente dos países do bloco europeu [...] A opção foi por regular cada setor de maneira estanque [...] O modelo europeu é considerado mais eficaz e tem servido como padrão universal, sendo copiado pela legislação de diversos outros países [...] A inexistência de uma lei geral de proteção de dados pessoais enfraquece a luta pela proteção da privacidade dos cidadãos norte-americanos (REINALDO FILHO, 2018, p.136).

Não é demais destacar que as gigantes do ramo tecnológico possuem seu nascedouro nos EUA, em especial no Vale do Silício, se o lobby dessas empresas por todo o mundo já é avassalador imagine o que ocorre "em casa". Some-se a isso a obsessão histórica do governo americano pelo poder e domínio mundial. Talvez estes itens respondam o porquê de uma tratativa mais branda da questão por lá.

O Brasil se apresenta na vanguarda das regulamentações do mundo digital, muito ainda há para fazer, mas temos legislações importantes sobre o tema. Primeiro foi o Marco Civil da Internet (Lei 12.965/2014) que não é uma lei especificamente voltada para proteção de dados, mas que já trata do tema.

Nessa perspectiva, o direito digital pode ser compreendido enquanto uma inovação dentro do direito de modo a envolver aspectos sociais com características inovadoras referentes a proteção do ser humano, de forma que a navegação seja segura contra fraudes, abrangendo a existência de princípios e diretrizes que precisam ser respeitadas também dentro do ambiente virtual, isso porque o anonimato da internet não é uma ferramenta impossível de ser modificada.

Segundo Pinheiro (2016), "o mundo digital é largamente afetado com a promulgação da Lei do Marco Civil da Internet, cuja pretensão é proteger e garantir maior privacidade e maior liberdade ao internauta enquanto usuário dos serviços". Nesse sentido, o autor afirma que o Marco Civil da Internet tratou do princípio da neutralidade de rede, o qual consiste em garantir igualdade no tráfego de 
dados, em cujo ambiente todos devem ter acesso igualitário às informações veiculadas e disponibilizadas, seja pelo próprio agente ou por terceiros, sem preferência ao direito.

Agora temos a LGPDP - Lei Geral de Proteção de Dados Pessoais (Lei 13.709/2018) totalmente inspirada na Regulamentação Europeia do tema. Tal legislação específica sobre o tema de dados pessoais foi sancionada em 14 de agosto de 2018 e vem sofrendo diversas alterações e prorrogações do seu período de vacatio legis prorrogado. Tal legislação tem como princípio basilar a dignidade da pessoa humana, assim como os direitos fundamentais de liberdade, privacidade e livre desenvolvimento da pessoa natural, protegendo os dados pessoais e trazendo a obrigatoriedade de ciência clara e consentimento para uso especificado de tais. "A Lei surge como proteção de dados pessoais, trazendo consigo medidas gerais de direitos e obrigações no que se refere ao usufruto da Internet no país, mas especificamente quanto a tutela de dados de seus usuários" (RIBEIRO, 2019, p. 195).

A legislação supracitada é estruturada em 10 capítulos, em um total de 65 artigos. A legislação em questão é autoexplicativa, trazendo em seu texto todos os conceitos, princípios e fundamentos que a norteiam. Dispõe sobre o tratamento de dados, por pessoa natural ou jurídica, de direito público e privado, como já mencionado objetivando a proteção dos direitos fundamentais de liberdade, privacidade e livre desenvolvimento da personalidade.

Necessário é observar que a Lei em tela em seu artigo $4^{\circ}$, inciso III c/c o parágrafo $1^{\circ}$ do mesmo artigo excetuam o Estado na atividade de segurança pública, defesa nacional, segurança do Estado ou atividades de investigação e repressão de infrações penais a seguiram o que a mesma disciplina, deixando claro que o tema será regido por legislação específica. Importante observarmos, pois tal norma ainda não foi apresentada e/ou aprovada pelas casas legislativas e a preocupação referente a proteção dos direitos do cidadão e não vigilância ilícita e abusiva se estende ao Estado, que já provou pela história das ditaduras que pode ser nosso maior algoz.

A LGPD também traz os conceitos específicos e relevantes para sua compreensão, são eles: dado pessoal; dado pessoal sensível; dado anonimizado; banco de dados; titular; controlador; operador; encarregado; agentes de tratamento; anonimização; consentimento; bloqueio; transferência internacional de dados; uso compartilhado de dados; relatório de impacto à proteção de dados pessoais; órgãos de pesquisa; e autoridade nacional. Isso é importante para que a intepretação dela possa ser a mais uniforme possível, reduzindo a insegurança jurídica do sobre o tema.

Em alteração da norma em tela a Lei 13.853/2019 trouxe modificações e outras disposições ao texto, sendo a principal a criação da Autoridade Nacional de Proteção de Dados (ANPD) a quem cabe, entre outras funções, elaborar as diretrizes da Política Nacional de Proteção de Dados Pessoais e da Privacidade.

\section{DADOS COMO NOVO DIREITO FUNDAMENTAL}

A defesa de direitos e garantias do cidadão deve perpassar por diversas pre- 
ocupações nos mais variados nichos: educacional, assistencial e relacionado à saúde. Há agora a compreensão de que a proteção de dados dentro da nova era tecnológica também precisar ser abarcada, temos de voltar a origem para garantir a individualidade, a liberdade individual a cada identidade e a própria liberdade relacionada ao acervo intelectual, que abrange desde as informações e conhecimentos, e conversas daquilo que lhe é mais íntimo.

A sociedade passou por diversas evoluções relacionadas ao contexto social, político e tecnológico, e na atualidade a questão tecnológica ganhou um papel de destaque principalmente através das redes sociais, de modo que o tema em pauta versa sobre a possibilidade ou existência de afirmar o nascimento de um novo direito fundamental no âmbito digital.

A discussão sobre a fundamentalidade da proteção de dados pessoais surge a muito e se intensifica na sociedade tecnológica, isso porque em todo mundo existe uma dificuldade em realizar a proteção dos dados, todos estamos expostos a esses tipos fortuitos, e essa dependência tecnológica exacerbada que cresce na medida em que a sociedade evolui, porém, com mais intensidade, leva a situação de risco e exposição cada vez mais dinâmicas e mais graves. Surgem, então, novas questões:

Ser humano ou produto? A utilização dos dados pessoais no âmbito comercial nos traz diversos aspectos que precisam ser estudados, principalmente relacionados a preservação das relações intersociais, e com a exposição trazida pela internet é possível notar que com os dados na web, encontrar características pessoais tornou-se cada vez mais fácil, principalmente quando se realiza uma pesquisa no Google.

Nesse aspecto é que se levanta a questão da venda de dados das mídias sociais, para empresas principalmente de vendas online, o Facebook fora uma das primeiras mídias sociais a enfrentar uma situação de escândalo, no que se refere a venda de dados de seus usuários, de modo a selecionar qual o público alvo de cada tipo de comércio, vejamos uma matéria do Jornal do Comércio da Globo:

A polêmica envolvendo a venda de dados dos usuários do Facebook por empresas de consultoria vai afetar em cheio as receitas da maior rede social do mundo, ao colocar em xeque seu modelo de negócios, calcado em publicidade por meio da segmentação dos dados de seus internautas. A desconfiança vem tanto das empresas quanto dos usuários da rede social. De acordo com especialistas, grandes anunciantes globais já entraram em contato com agências de propaganda mostrando preocupação com a sustentabilidade da empresa fundada por Mark Zuckerberg. O escândalo do caso Cambridge Analytica, que teria usado informações de 50 milhões de usuários do Facebook em prol da campanha de Donald Trump à presidência dos Estados Unidos, em 2016, terá como efeito a cautela das empresas na hora de gastar com propaganda na rede social. (GLOBO, 2019).

Independente de aspectos políticos, há que se ressaltar que a venda de dados dos usuários é considerada uma forma de desumanização. Isso porque os usuá- 
rios passam a ser considerados mercadorias nas redes que deveriam se restringir a aspectos relacionados a envolvimentos virtuais, a permissão de repasse desses dados deve depender de anuência de cada usuário, porém de forma clara, isso porque os contratos que geralmente são aceitos pelos usuários são de adesão e se quer são lidos, e isso é a realidade da sociedade brasileira.

Mesmo compreendendo, que diversas formas de fraudes poderiam ser evitadas com a leitura de normas, discussão sobre cláusulas ou até mesmo a não adesão, muitas pessoas optam por aceitar as diretrizes sem realizar a devida leitura, nesse aspecto o próprio homem estaria contribuindo para essa desvalorização do ser humano corroborando para que seja tratado como mercadoria.

Privacidade hackeada? Quando se busca abordar as características de uma Privacidade Hackeada há que se tratar do documentário, de mesmo nome, estreado na Netflix levando em consideração os escândalos com a questão da venda de dados dos usuários de redes sociais, uma forma de violação da privacidade deles. O famoso escândalo da Cambrigde Analytica e do Facebook. A Cambridge Analytica, assessoria britânica que trabalhou para a campanha eleitoral do presidente americano, Donald Trump, enfrentou um escândalo isso porque houve uma assistência política que dirigiu a campanha digital de Trump em 2016 utilizando um aplicativo para coletar informações privadas de 87 milhões de usuários sem seu conhecimento. A privacidade dos usuários nestes casos foi violada e seus dados utilizados de maneira indevida.

No decorrer do processo a empresa foi condenada por um tribunal de Londres a multa de 15 mil libras (US\$19,1 mil ou 16,7 mil euros) e terá ainda de pagar os custos do processo, no valor de 6 mil libras. O Facebook já havia admitido que a Cambridge Analytica utilizou estes dados para mandar aos usuários publicidade política especialmente adaptada e elaborar informes detalhados para ajudar Trump a ganhar a eleição contra a candidata democrata Hillary Clinton.

$\mathrm{O}$ direito brasileiro deve buscar proteger seus cidadãos de quaisquer tipos de ameaças existentes, sejam elas físicas ou tecnológicas, como ocorrido nessas diretrizes do Facebook, nesse aspecto as normas jurídicas buscam cada vez mais compreender o mercado tecnológico e como conseguir realizar a devida fiscalização em um sistema tão complexo capaz de quantificar e extrair informações extremamente pessoais de seus usuários.

Os bancos digitais, lojas, mercados, e dentre tantas outras plataformas existentes e com fácil acesso e ao alcance das mãos levam o usuário a fornecer informações básicas ou até mesmo complexas como Cadastro de Pessoa Física, Registro Geral, datas de nascimento e casamento, que são dados que precisam ser protegidos de alguma forma tanto pelo sistema jurídico quanto pelas próprias pessoas.

A Magna Carta Brasileira em seu artigo $5^{\circ}$, inciso $X$ garante a inviolabilidade da intimidade, da vida privada, da honra e da imagem das pessoas. Soma-se a isso a importância para existência humana, do eu íntimo, desconhecido ou conhecido apenas por poucos que assim escolhemos nos mostrar. O personagem David Carroll faz esta reflexão no documentário trazendo também a preocupação, não 
apenas da manipulação presente, mas dos impactos que o uso de informações pessoais pode causar à pessoa em toda sua existência e em seus familiares, ferindo a imagem do indivíduo até mesmo depois de sua morte. Daí a importância das leis de proteção e uso de dados pessoais.

Liberdade vigiada? Compreender os aspectos de uma liberdade vigiada é entender que existe, na interface digital, uma forma camuflada de rastrear seus passos, dados, conexões familiares e assim, de alguma maneira lhes vigiar. As empresas que controlam as redes sociais vêm ganhando muito dinheiro em acordos comerciais com dezenas de serviços online, sem consultar ou receber autorização expressa dos usuários das suas plataformas, de forma mais ou menos consciente, entregam uma vasta quantidade de dados pessoais para os mais diversos fins.

É difícil superestimar a escala da transformação econômica desencadeada por esta economia da vigilância. Até mesmo empresas de setores tradicionais estão sendo transformadas em veículos para coleta de dados pessoais. Companhias aéreas, por exemplo, agora são mais do que apenas um meio de transporte. Também são empresas de coleta de dados e marketing ligadas a outras empresas de coleta de dados e marketing, como redes hoteleiras, companhias de táxi, agências de viagem, empresas de cartões de crédito e bancos. Programas de fidelidade oferecem maneiras de rastrear preferências, movimentações e hábitos de consumo de seus clientes.

Embora muitas pessoas reconheçam as limitações reais das nossas escolhas, um estudo global com estudantes que tentaram passar um dia sem acessar redes sociais (leia-se mídias sociais) evidenciou um mecanismo muito mais fundamental (e menos consciente). De acordo com este estudo:

[...] a maioria dos estudantes de todos os [dez] países não conseguiu passar 24 horas sem acessar nenhuma rede social, e todos usaram praticamente as mesmas palavras para descrever suas reações: inquieto, confuso, ansioso, irritável, inseguro, nervoso, impaciente, louco, viciado, apavorado, enciumado, furioso, solitário, dependente, deprimido, agitado e paranoico (NEW STUDY, 2011).

Assim, as redes sociais são mecanismos de vício, mas também de insegurança jurídica para seus usuários.

Democracia manipulada? Ao falarmos em democracia manipulada destacamos o fato da utilização de dados para análise de perfis e direcionamento do material publicitário dos candidatos aos eleitores categorizados menos favoráveis ao candidato em questão. É o que o documentário Privacidade Hackeada sugere que ocorreu na campanha de Trump, do Brexit e até mesmo anos atrás, e de maneira sutil, na campanha de Obama, e bem recentemente aqui no Brasil nas últimas eleições presidenciais quando vimos o uso massivo das redes sociais pelos candidatos, em especial na campanha do então candidato Bolsonaro, hoje presidente do Brasil.

Quando se busca tratar de uma perspectiva de democracia manipulada, há que se compreender que para os operadores do direito a imparcialidade é requisi- 
to essencial ao desenvolvimento de uma análise, seja qual for o nível acadêmico, a defesa de sistemas políticos de esquerda ou direita não pode fundamentar aspectos relacionados a utilização de dados em campanhas políticas.

Isso porque tanto os partidos de esquerda, quanto de direita ao longo do mundo em que existe instaurada uma democracia, monarquia ou qualquer outro sistema de governo, a utilização de dados é existente, seja de forma lícita ou de forma invasiva.

De fato, para compreendermos uma democracia manipulada seria necessário a apresentação de dados que comprovassem tal utilização, a especulação de jornais tendenciosos para ambos os lados políticos não pode servir de fonte para uma argumentação jurídica.

Assim, a proteção de dados enquanto direito autônomo, dá diretrizes para todos reivindicarem um tratamento justo, com respeito aos dados de modo que as propagandas existentes nas mídias sociais sejam relacionadas aos mais variados temas e não apenas a questões políticas ou quaisquer outras formas de manipulação existente. Mas se deve ressaltar que propaganda que expresse a manifestação de pensamento não dá salvo conduto para disseminação de inverdades, as chamadas fakes news.

\section{PROTEÇÃO DE DADOS PESSOAIS COMO UM DIREITO AUTÔNOMO E FUNDAMENTAL}

Tratar sobre a proteção de dados pessoais sob a perspectiva de direito autônomo é compreender a fundamental contribuição dessa proteção para o resguardo de aspectos relacionados ao ser humano em um contexto geral, há que se ressaltar que existe a tutela jurídica da proteção de dados pessoais, no Brasil, através da promulgação da Lei 13.709, de 14/8/18.

Compreendemos que no artigo o art. $1^{\circ}$, da lei tem por objetivo promover a proteção dos direitos fundamentais de liberdade, privacidade e do livre desenvolvimento da personalidade, isso porque existe a necessidade de afunilamento do tratamento de dados pessoais realizado por pessoas ou empresas, reconhecendo tratar-se de novo fenômeno ínsito à era digital.

Há que se ressaltar aspectos relacionados ao direito à privacidade que pode ser compreendido segundo dispõe Tércio Sampaio Ferraz Jr. (1998, p. 442) como "um direito subjetivo fundamental, cujo titular é toda pessoa física ou jurídica [...] cujo conteúdo é a faculdade de constranger os outros ao respeito e de resistir à violação do que lhe é próprio [...]; e cujo objeto é a integridade moral do titular".

Nos dizeres de Facchini Neto e Demoliner (2018):

Reagindo a essa situação, observa-se que na sociedade europeia, para além da previsão tradicional de proteção à privacidade em sua concepção clássica / original, a Carta da União Europeia "inovou" ao incluir o direito à proteção de dados, alçando-o à categoria de direito fundamental autônomo. É o que se depreende da leitura conjugada dos arts. 
$3^{\circ}$ (direito à integridade da pessoa, isto é, proteção do "corpo físico"), $7^{\circ}$ (direito de respeito da vida privada e familiar - concepção 'clássica' de privacidade), e art. $8^{\circ}$ (direito à proteção de dados, ou seja, "corpo eletrônico" (FACCHINI NETO; DEMOLINER, 2018). - grifos do autor.

Percebemos uma preocupação, e uma compreensão de uma crise que viria anos depois com a evolução da tecnologia sobre a importância de resguardar a integridade moral do indivíduo seja ele uma pessoa física ou jurídica de violações de dados, ou outros aspectos que de alguma forma lhe sejam individualizados. Assim, no mesmo sentido compreende-se a evolução do direito a partir de uma postura omissiva do poder público em face ao cidadão, para uma totalmente diversa, e voltada principalmente a massificação do tratamento, viabilizada pelas tecnologias digitais.

Nesse aspecto, compreender a amplitude dessa legislação para preservação dos dados pessoais dos usuários é de extrema importância, principalmente porque se busca impor limites à "ilimitável" internet, a tecnologia não pode se sobrepujar as diretrizes humanas ela é fruto de uma criação humana que precisa ser analisada e contribuir para melhora na vida em sociedade e não se tornar um fardo para coletividade.

Dessa forma, deve ser garantida a observância dos princípios dispostos no art. $6^{\circ}$, LGPD, tais como o da finalidade, o da necessidade e o da adequação, a dogmática possibilita o legítimo proveito econômico, o desenvolvimento e a inovação decorrentes das atividades de coleta e tratamento de dados pessoais. Portanto, assim como todo direito fundamental, a proteção de dados pessoais não possui caráter absoluto, podendo também ser objeto de limitações.

Dessa feita, há que se ressaltar o reconhecimento da proteção de dados pessoais, como um direito fundamental que precisa ser concebido por uma perspectiva constitucional, no sentido de promover através do status de direito fundamental autônomo, para promover aos cidadãos brasileiros à proteção irrestrita de seus dados, assim, é possível concluir ser necessário, em favor da segurança jurídica, comissionar, constitucionalmente, a União como único ente federado responsável por desempenhar o papel regulatório da matéria, delegando-lhe competência privativa, por meio de explicitação no artigo 22 da CF/ 88 .

Pensando nas questões atuais que vivemos diante das novas tecnologias, bem como nas que ainda virão, e que somos incapazes de prever todas, é que alertamos para que o Legislativo eleve a proteção de dados à condição de direito fundamental autônomo constitucionalmente previsto. Dado seu caráter eterno no mundo digital e o impacto que seu uso causa as pessoas, violando também tantos outros direitos fundamentais constitucionalmente protegidos.

Todo fato que a ausência de sua tutela jurídica traga ao homem uma condição de vulnerabilidade merece ser protegido. Em que a ausência de sua tutela coloque o princípio da dignidade humana em risco merece ser tutelado como direito fundamental.

Assim, a proteção de dados pessoais merece ser erigida a tutela de direito 
fundamental, pois, na atualidade da era da tecnologia, que viabiliza o capitalismo de dados, são claros os riscos ao homem, tanto como indivíduo digno de proteção, como enquanto sociedade que deve ter o Estado de Direito e a Democracia preservados hoje e para as gerações futuras.

Vivemos uma era de avanços tecnológicos, mas nem tudo irá mudar, e muito menos na velocidade com que se noticia. Pensamos que há dois elementos fundamentais nesta composição, elementos que sempre subsistiram na história da humanidade e que entendemos que assim permanecerão: o primeiro é que o homem em sua essência sempre será humano e nisso nunca será substituído por máquinas e robôs; o segundo é que para que grandes mudanças sociais ocorram, como as evoluções tecnológicas, nós humanos precisamos estar preparados e convencidos de que seus benefícios são maiores que seus males, e muito do que se fala de tecnologias do futuro, para a maioria de nós ainda é algo assustador e coisa de seriados blockbuster.

Acreditamos, ainda, mais no humano e em nossa necessidade, acima de tudo, de sermos felizes, buscando a voz da justiça, em especial, para aqueles que não tem voz. E isso faremos com ou sem robôs.

\section{REFERENNCIAS}

BARROSO, Luís Roberto. Curso de Direito Constitucional Contemporâneo. 3. ed. São Paulo: Saraiva, 2011.

. Curso de Direito Constitucional contemporâneo: os conceitos fundamentais e a construção do novo modelo. São Paulo: Saraiva, 2009.

BAUMAN, Zygmunt; LYON, David. Liquid surveillance: A conversation. John Wiley \& Sons, 2013.

BOBBIO, Norberto. A era dos direitos. Nova ed. Rio de Janeiro: Elsevier, 2004.

CANOTILHO, José Joaquim Gomes. Direito constitucional e teoria da Constituição. 6. ed. rev. Coimbra: Almedina, 1993.

CARIBÉ, João Carlos. Uma perspectiva histórica e sistêmica do capitalismo de vigilância. Revista Inteligência Empresarial, n. 41, 2019.

FACCHINI NETO, Eugênio; DEMOLINER, Karine Silva. Como os Tribunais Superiores vêm honrando a Constituição Cidadã: o caso do direito à imagem. Revista de Informação Legislativa, v. 55, n. 219, 2018.

FERRAJOLI, Luigi. Derecho y razón: teoría del garantismo penal. Madrid: Trotta, 1995.

GLOBO. Jornal do Comércio. Polêmica envolvendo venda de dados por Facebook gera debate sobre futuro da rede.2019. Disponível em: https:/ / www.jornaldocomercio.com/_ conteudo/2018/03/economia/617787-polemica-envolvendo-venda-de-dados-por-facebook-gera-debate-sobre-futuro-da-rede.html. Acesso em: 10 nov. 2019.

LEAL, Fábio Gesser; SABINO, Rafael Giordani. Direitos Fundamentais: uma breve visão 
panorâmica. Revista Âmbito Jurídico, 2017.

MASCARENHAS, Paulo. Manual de direito constitucional. 2010.

MORAES, Guilherme Peña de. Curso de Direito Constitucional. 9. ed. São Paulo: Atlas, 2017.

NETFLIX. Privacidade Hackeada. 2018. Acesso em: 20 out. 2019.

NEW STUDY. "New Study By Merrill Prof Finds Students Everywhere Addicted To Média. Disponível em: https://merrill.umd.edu/2011/04/new-merrill-study-finds-students- everywhere-addicted-to-media.

PINHEIRO, Patrícia Peck. Espionagem digital e legal. In: PINHEIRO, Patrícia Peck (coord.). Direito digital aplicado 2.0. 2. ed. São Paulo: Thomson Reuters, 2016.

PUPO, Álvaro Carvalho Pinto. Privacidade, Liberdade de Expressão e Proteção dos Dados Pessoais - uma perspectiva brasileira com base na jurisprudência do Supremo Tribunal Federal / Álvaro Carvalho Pinto Pupo. São Paulo. 2017.

REINALDO FILHO, Demócrito. EUA se preparam para aprovar lei sobre proteção de dados pessoais semelhante à europeia?. Revista Jus Naveganti, n. 23, 2018.

RIBEIRO, Alfredo Rangel. A lei geral de proteção de dados pessoais brasileira como meio de efetivação dos direitos de personalidade. 2019. 53 f. Trabalho de Conclusão de Curso (Graduação em Direito). Universidade Federal da Paraíba, João Pessoa, 2019.

SARLET, Ingo Wolfgang. Eficácia dos direitos fundamentais. 13. ed. São Paulo: Livraria do Advogado, 2018.

SHEDD, Russel. Bíblia Shedd: Antigo e Novo Testamentos. Traduzida por João Ferreira de Almeida, v. 2, 1997.

SILVA, Flavia Martins André da. Direitos Fundamentais. 2006. Disponível em: https:/ / www.direitonet.com.br/artigos/exibir/2627/Direitos-Fundamentais. Acesso em: 24 ago. 2019.

SILVA, José Afonso. Curso de direito constitucional positivo, v. 13, 2005.

ZUBOFF, Shoshana. Tua escova de dentes te espiona: Um capitalismo de vigilância. Editora: Mundo. Revista Le Monde Diplomatique Brasil. Edição - 138, 2019. Disponível em: https://diplomatique.org.br/um-capitalismo-de-vigilancia/. Acesso: 30 nov. 2019. 